Article

\title{
Rapid Screening of Forskolin-Type Diterpenoids of Blumea aromatica DC Using Ultra-High-Performance Liquid Chromatography Tandem Quadrupole Time-Of-Flight Mass Spectrometry Based on the Mass Defect Filtering Approach
}

\author{
Lili He ${ }^{1}$, Zhifeng Zhang ${ }^{2}$, Caiyun Yao ${ }^{1}$, Jianhua Miao ${ }^{1}$, Bingxiong Yan ${ }^{1}$, Lingling Wu ${ }^{1}$, \\ Limei Pan ${ }^{1}$, Zhijun Song ${ }^{1, *}$ and Shugen Wei ${ }^{1, *}$ \\ 1 National Engineering Institute for the Research and Development of Endangered Medicinal Resources in \\ Southwest China, Guangxi Botanical Garden of Medicinal Plants, Nanning 530023, China \\ 2 Institute of Qinghai-Tibetan Plateau, Southwest University for Nationalities, Chengdu 610041, China \\ * Correspondence: songzj430@aliyun.com (Z.S.); weishugen2@163.com (S.W.); \\ Tel.: +86-771-5602461 (Z.S.); +86-771-2443050 (S.W.)
}

Received: 23 July 2019; Accepted: 20 August 2019; Published: 23 August 2019

check for updates

\begin{abstract}
The discovery of new active compounds of natural products tends to be increasingly more challenging due to chemical complexity and unpredictable matrices. Forskolin is an active natural labdane-type diterpenoid ingredient widely used worldwide for the treatment of glaucoma, heart failure, hypertension, diabetes, and asthma, and is expected to be a promising anticancer, anti-inflammation, and anti-HIV agent. In recent years, demand for forskolin in the medicine market has increased dramatically. However, natural forskolin originates exclusively from traditional Indian herb medicine Coleus forskohlii (Willd.) Briq. In a previous study, we isolated a series of diterpenoids including an 8,13-epoxy-14ene labdane carbon skeleton from Blumea aromatica DC. In order to identify alternative plant resources, a novel and effective strategy was proposed for the screening of potential forskolin-type diterpenoids (FSKD) compounds obtained from B. aromatica, using the mass defect filtering (MDF) strategy via ultra-high-performance liquid chromatography tandem quadrupole time-of-flight mass spectrometry (UHPLC-QTOF/MS) approach. Within a narrow, well-defined mass defect range, the strategy developed could significantly improve the detection efficiency of selected FSKD compounds by filtering out certain major or moderate interference compounds. Additionally, the MS/MS cleavage behavior and the characteristic diagnostic ions of the FSKD compounds were proposed to be used in aiding structural identification of the filtration compounds. As a result, a total of 38 FSKD of B. aromatica were filtered out and tentatively identified. To the best of our knowledge, it was the first time that these forskolin-type diterpenoids were identified in B. aromatica, which significantly expands our understanding of the chemical constituents of Blumea species, and allows B. aromatica to be used as a potential alternative plant resource that contains these forskolin-type active compounds. The strategy proposed was proven efficient and reliable for the discovery of novel compounds of herbal extracts.
\end{abstract}

Keywords: Blumea aromatica DC; foskolin; diterpenoids; mass defect filter; UHPLC-QTOF-MS/MS

\section{Introduction}

It is well known that natural products, particularly those with novel chemical structures, are recognized as playing an important role in the discovery of drugs that are beneficial for human health. However, it is still a great challenge to explore active constituents of natural sources due to the 
chemical diversity and complex matrices of natural products. The traditional phytochemistry approach, which involves the extraction, isolation, complicated chemical manipulations, and spectroscopic analysis of these active constituents is time-consuming and laborious, and also tends to result in the loss of minor or unstable components during the separation process.

Recently, ultra-high-performance liquid chromatography tandem with mass spectrometry (UHPLC-MS), especially with high-resolution mass spectrometry (HRMS), has begun to play an important role in the detection and identification of complex compounds used in traditional Chinese medicine (TCM) due to its high mass accuracy and resolution [1,2]. However, the main difficulty associated with structural identification may be the process used to acquire mass complex HRMS data. In previous reports, complex components of TCM have been detected and identified mainly based on MS/MS fragmentation, which is usually inefficient and labor-intensive, since it is usually done individually using manual processes. Additionally, this approach is largely dependent on the fragmentation patterns summarized from reference compounds [3,4]. It has made structural characterization more difficult, especially due to the lack of chemical standards. Furthermore, progress has been hindered further by the large number of interfering substances contained in crude herbal extracts.

Therefore, in order to rapidly detect and efficiently filter as many signals of interest as possible, a novel and effective data processing technique, the mass defect filtering (MDF) method has been explored. In fact, the identification of target compounds from a complex matrix using the MDF strategy has been used widely in MS data processing [5-7].

It is well known that active components of natural herbs always share a similar core carbon skeleton, with variations, such as hydroxyls, formyls, carbonyls, acetyls, and glycosylations, or a combination of these, in their chemical substitution groups. Theoretically, core substructures with different substituents always possess only relatively minor changes in their mass defect value. The mass defect profile of the compounds that share a similar carbon skeleton structure or substructure usually change within a limited range. Therefore, when analyzing a crude extract, a majority of interfering components can be excluded automatically from the complex samples by a defined MDF value which facilitate the identification of target structural analogues in TCM [8-10].

Forskolin, a labdane-type diterpenoid, is an active natural compound with a unique complex structure that originates from a well-known traditional Indian medicinal herb, Coleus forskohlii (Willd.) Briq. [11], which is used worldwide for the treatment of glaucoma, heart failure, hypertension, diabetes, and asthma based on its activity as a cyclic AMP booster [12,13], and is a promising anticancer [14,15], anti-inflammation [16,17], and anti-HIV [18] agent. Currently, commercial production of forskolin relies mainly on the extraction from its only known natural source, Coleus forskohlii, which is distributed in India and Southeast Asia [11]. At present, due to the significance of its activity, the market demand for forskolin will keep growing. However, reliable and sustainable commercial forskolin extraction from C. forskholii will become impossible due to the dramatic decrease of its natural source and low extraction yields. Great effort has been made globally to identify more natural sources containing forskolin type active compounds, in order to meet the market demand. However, as far as we know, there are only a few plants that have been identified to contain these active compounds [19].

Blumea aromatica DC., a traditional Chinese medicinal plant, known as Shanfeng in Chinese, belongs to the composite family and is a perennial herb widely distributed throughout Southwest China, as well as the southern and southeastern regions of Asia. Shanfeng has been widely used as traditional Chinese medicine for the treatment of rheumatism, arthralgia, and eczema. However, only a few detailed reports are available on the chemical properties of B. aromatica [20]. In our previously study, a total of five diterpenoid compounds were isolated from B. aromatica in our lab. It was notable that the structures of the diterpenoid isolated from $B$. aromatica shared a core skeleton which was similar to that of forskolin. As far as we know, this was the first time that these forskolin-type diterpenoid (FSKD) compounds were found in B. aromatica. 
In order to find more FSKDs and fully profile the FSKDs in B. aromatica, identify other alternative plant resources containing forskolin active ingredients, and understand the effective material basis and pharmacological activity of crude herbs, it is urgently required to develop a sensitive and reliable method to characterize the FSKD in B. aromatica. In this study, we describe an effective and facile approach for the overall capture of the FSKDs in B. aromatica based on UHPLC-QTOF/MS coupled with the MDF approach. For the first time, a total of 38 FSKDs were filtered out and tentatively identified from $B$. aromatica. It is expected that the Method and Results of the present study would expand our understanding of the chemical constituents of B. aromatica, and provide a helpful strategy to identify natural plant resources containing FSKD active components, as well as to be used as an effective tool to screen for chemical targets for future phytochemical and pharmacological activity studies on these important herbal medicines.

\section{Results}

According to the proposed screening strategy below, first, the MDF filtration method was established based on the FSKDs constituents which have been reported in Coleus forskohlii [21,22]. Secondly, the extract of B. aromatica sample was analyzed by UHPLC-QTOF-MS/MS at both positive and negative modes. Then, the developed MDF method was performed to pick out the potential precursor ions of the FSKDs. Finally, the structures of the screened compounds were further elucidated based on MS/MS spectra and fragmentation pathways were summarized using the reference substance (see Figure 1).

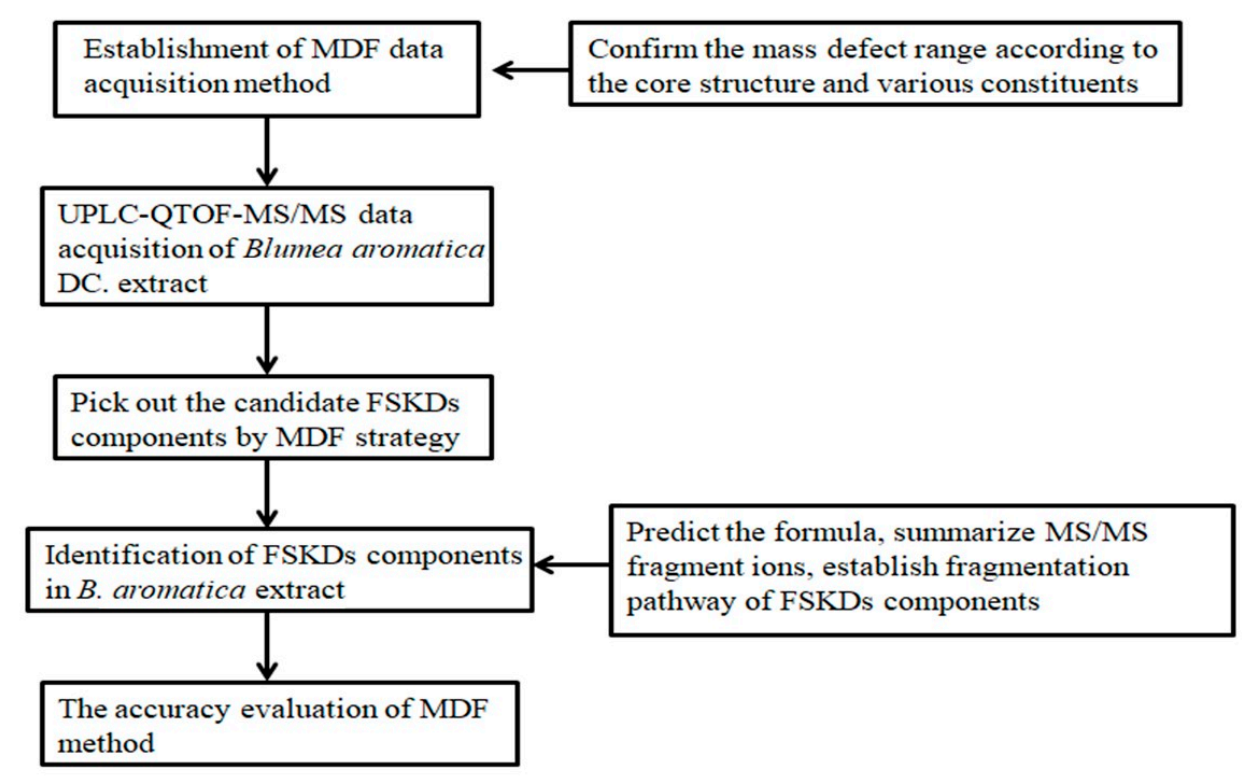

Figure 1. Flow diagram illustrating the approach used to screen forskolin-type diterpenoids from B. aromatica.

The base peak ion (BPI) chromatogram of the extraction of $B$. aromatica before and after MDF filtration is shown in Figure 4. In this study, a total of 38 FSKDs of the B. aromatica sample were selected and characterized (Table 1). 
Table 1. Foskolin-type diterpenoids of B. aromatica screened using the MDF method.

\begin{tabular}{|c|c|c|c|c|c|c|}
\hline \multirow{2}{*}{ Peak No. } & \multirow{2}{*}{$\begin{array}{c}\text { Retention Time } \\
\text { (min) }\end{array}$} & \multicolumn{2}{|c|}{$\mathrm{ESI}^{-}, \mathrm{m} / \mathbf{z}^{*}$} & \multirow{2}{*}{$\mathrm{ESI}^{+}, \mathrm{m} / \mathrm{z}$} & \multirow{2}{*}{ Formula } & \multirow{2}{*}{ MS/MS Fragment Ions in Positive Mode ** } \\
\hline & & {$[\mathbf{M}-\mathbf{H}]^{-}$} & {$\left[\mathrm{M}+\mathrm{COOH}^{-}\right.$} & & & \\
\hline 1 & 7.81 & 369.2282 & 415.2367 & $\begin{array}{c}388.2722\left[\mathrm{M}+\mathrm{H}_{2} \mathrm{O}\right]^{+} \\
393.2276[\mathrm{M}+\mathrm{Na}]^{+} \\
741.4863[2 \mathrm{M}+\mathrm{H}]^{+}\end{array}$ & $\mathrm{C}_{20} \mathrm{H}_{34} \mathrm{O}_{6}$ & $\begin{array}{l}353.2346,335.2242,317.2135,305.2133,299.2022,289.2181,287.2037 \\
275.2031,271.2077,259.2080,253.1980,237.1858,229.1974,221.1555\end{array}$ \\
\hline 2 & 7.95 & 369.2274 & 415.2335 & $\begin{array}{c}393.2271[\mathrm{M}+\mathrm{Na}]^{+} \\
741.4832[2 \mathrm{M}+\mathrm{H}]^{+} \\
763.4637[2 \mathrm{M}+\mathrm{Na}]^{+}\end{array}$ & $\mathrm{C}_{20} \mathrm{H}_{34} \mathrm{O}_{6}$ & $\begin{array}{c}353.2341,335.2237,317.2133,299.2029,289.2183,287.2025,275.2028 \\
271.2073,259.2076,255.2122,253.1950,221.1556\end{array}$ \\
\hline 3 & 8.30 & 369.2273 & 415.2336 & $\begin{array}{c}388.2710\left[\mathrm{M}+\mathrm{H}_{2} \mathrm{O}\right]^{+} \\
393.2259[\mathrm{M}+\mathrm{Na}]^{+} \\
741.4811[2 \mathrm{M}+\mathrm{H}]^{+}\end{array}$ & $\mathrm{C}_{20} \mathrm{H}_{34} \mathrm{O}_{6}$ & $\begin{array}{c}353.2343,335.2233,317.2122,305.2129,299.2018,289.2175,287.2021 \\
275.2022,271.2075,259.2068,253.1958,229.1965,221.1552\end{array}$ \\
\hline 4 & 8.40 & 369.2279 & 415.2338 & $\begin{array}{c}388.2710\left[\mathrm{M}+\mathrm{H}_{2} \mathrm{O}\right]^{+} \\
393.2260[\mathrm{M}+\mathrm{Na}]^{+} \\
741.4801[2 \mathrm{M}+\mathrm{H}]^{+} \\
763.4626[2 \mathrm{M}+\mathrm{Na}]^{+}\end{array}$ & $\mathrm{C}_{20} \mathrm{H}_{34} \mathrm{O}_{6}$ & $\begin{array}{c}353.2345,335.2234,317.2120,305.2132,299.2014,289.2176,287.2024 \\
275.2027,271.2075,259.2065,253.1952,229.1965,221.1556\end{array}$ \\
\hline 5 & 9.19 & 351.2180 & 397.2241 & $\begin{array}{c}370.2602\left[\mathrm{M}+\mathrm{H}_{2} \mathrm{O}\right]^{+} \\
375.2152[\mathrm{M}+\mathrm{Na}]^{+} \\
705.4606[2 \mathrm{M}+\mathrm{H}]^{+} \\
727.4465[2 \mathrm{M}+\mathrm{Na}]^{+}\end{array}$ & $\mathrm{C}_{20} \mathrm{H}_{32} \mathrm{O}_{5}$ & $\begin{array}{c}335.2232,317.2122,305.2121,299.2022,289.2179,287.2014,275.2006 \\
271.2074,255.2113,253.1974,221.1557,175.1492\end{array}$ \\
\hline 6 & 9.29 & 351.2178 & 397.2248 & $\begin{array}{c}\left.\text { 370.2602[M+ }{ }_{2} \mathrm{O}\right]^{+} \\
375.2159[\mathrm{M}+\mathrm{Na}]^{+} \\
705.4611[2 \mathrm{M}+\mathrm{H}]^{+} \\
727.4465[2 \mathrm{M}+\mathrm{Na}]^{+}\end{array}$ & $\mathrm{C}_{20} \mathrm{H}_{32} \mathrm{O}_{5}$ & $\begin{array}{c}335.2232,317.2122,305.2121,303.2323,299.2022,289.2179,287.2021 \\
275.2006,271.2074,259.2070,253.1974,221.1557,175.1491\end{array}$ \\
\hline 7 & 10.93 & 351.2176 & 397.2245 & $\begin{array}{c}370.2604\left[\mathrm{M}+\mathrm{H}_{2} \mathrm{O}\right]^{+} \\
375.2155[\mathrm{M}+\mathrm{Na}]^{+} \\
705.4610[2 \mathrm{M}+\mathrm{H}]^{+} \\
727.4466[2 \mathrm{M}+\mathrm{Na}]^{+}\end{array}$ & $\mathrm{C}_{20} \mathrm{H}_{32} \mathrm{O}_{5}$ & $\begin{array}{c}335.2235,317.2125,305.2120,303.2328,299.2020,289.2176,275.2010 \\
271.2071,259.2073,253.1970,221.1553\end{array}$ \\
\hline 8 & 11.74 & 307.1905 & 353.1953 & $\begin{array}{c}309.2070[\mathrm{M}+\mathrm{H}]^{+} \\
326.2342\left[\mathrm{M}+\mathrm{H}_{2} \mathrm{O}\right]^{+} \\
331.1891[\mathrm{M}+\mathrm{Na}]^{+}\end{array}$ & $\mathrm{C}_{18} \mathrm{H}_{28} \mathrm{O}_{4}$ & $291.1969,273.1863,263.2017,255.1757,245.1913,227.1808,221.1551$ \\
\hline 9 & 12.12 & 353.233 & 399.2389 & $377.2291[\mathrm{M}+\mathrm{Na}]^{+}$ & $\mathrm{C}_{20} \mathrm{H}_{34} \mathrm{O}_{5}$ & $\begin{array}{c}337.2320,319.2272,301.2164,289.2163,273.2215,271.2060,253.1949 \\
221.1548,175.1482\end{array}$ \\
\hline 10 & 12.36 & 353.233 & 399.2389 & --- & $\mathrm{C}_{20} \mathrm{H}_{34} \mathrm{O}_{5}$ & $\begin{array}{c}337.2322,319.2274,301.2160,289.2165,273.2210,271.2061,253.1946 \\
221.1545,175.1484\end{array}$ \\
\hline 11 & 12.38 & 365.1948 & 411.2001 & --- & $\mathrm{C}_{20} \mathrm{H}_{30} \mathrm{O}_{6}$ & $349.2005,319.2261,301.2149,273.2208,255.2085,221.1521,175.1489$ \\
\hline
\end{tabular}


Table 1. Cont.

\begin{tabular}{|c|c|c|c|c|c|c|}
\hline \multirow{2}{*}{ Peak No. } & \multirow{2}{*}{$\begin{array}{l}\text { Retention Time } \\
\quad(\text { min) }\end{array}$} & \multicolumn{2}{|c|}{$\mathrm{ESI}^{-}, \mathrm{m} / \mathbf{z}^{*}$} & \multirow{2}{*}{$\mathrm{ESI}^{+}, \mathrm{m} / \mathbf{z}$} & \multirow{2}{*}{ Formula } & \multirow{2}{*}{ MS/MS Fragment Ions in Positive Mode ** } \\
\hline & & {$[\mathbf{M}-\mathbf{H}]^{-}$} & {$[\mathrm{M}+\mathrm{COOH}]^{-}$} & & & \\
\hline 12 & 12.76 & 353.2316 & 399.2379 & --- & $\mathrm{C}_{20} \mathrm{H}_{34} \mathrm{O}_{5}$ & $\begin{array}{c}337.2365,319.2250,301.2152,289.2156,279.1592,273.2215,259.2047 \\
255.2110,253.1702,221.1533,175.1490\end{array}$ \\
\hline 13 & 14.36 & 353.2319 & 399.2379 & $377.2271[\mathrm{M}+\mathrm{Na}]^{+}$ & $\mathrm{C}_{20} \mathrm{H}_{34} \mathrm{O}_{5}$ & $\begin{array}{c}337.2360,319.2256,301.2150,289.2159,279.1590,273.2212,259.2053 \\
255.2111,253.1703,221.1535,175.1488\end{array}$ \\
\hline 14 & 14.96 & 335.2217 & 381.2268 & --- & $\mathrm{C}_{20} \mathrm{H}_{32} \mathrm{O}_{4}$ & $\begin{array}{c}319.2276,301.2173,287.2014,289.2154,273.2222,269.1906,255.2115 \\
221.1545\end{array}$ \\
\hline 15 & 14.98 & 349.2011 & 395.2065 & --- & $\mathrm{C}_{20} \mathrm{H}_{30} \mathrm{O}_{5}$ & 333.2071, 315.1973, 287.2030, 269.1908, 255.2138, 227.1819, 221.1565 \\
\hline 16 & 15.28 & --- & --- & $634.5107\left[2 \mathrm{M}+\mathrm{H}_{2} \mathrm{O}\right]^{+}$ & $\mathrm{C}_{19} \mathrm{H}_{32} \mathrm{O}_{3}$ & $291.2344,273.2238,255.2130,207.1768,199.1505,191.1453,175.1503$ \\
\hline 17 & 15.63 & 335.2231 & 381.2283 & --- & $\mathrm{C}_{20} \mathrm{H}_{32} \mathrm{O}_{4}$ & $\begin{array}{c}319.2298,301.2192,283.2084,273.2283,255.2133,221.1560,207.1770 \\
189.1659,175.1502\end{array}$ \\
\hline 18 & 16.25 & 333.2078 & 379.2132 & $\begin{array}{c}335.2216[\mathrm{M}+\mathrm{H}]^{+} \\
357.2035[\mathrm{M}+\mathrm{Na}]^{+} \\
331.2238[\mathrm{M}+\mathrm{Na}]^{+} \\
639.4576[2 \mathrm{M}+\mathrm{Na}]^{+}\end{array}$ & $\mathrm{C}_{20} \mathrm{H}_{30} \mathrm{O}_{4}$ & $\begin{array}{c}317.2112,299.2007,289.2163,271.2057,253.1952,243.2113,221.1542 \\
175.1483,161.1327,145.1014\end{array}$ \\
\hline 19 & 16.43 & --- & --- & $\begin{array}{l}331.2238[\mathrm{M}+\mathrm{Na}]^{+} \\
639.4576[2 \mathrm{M}+\mathrm{Na}]^{+}\end{array}$ & $\mathrm{C}_{19} \mathrm{H}_{32} \mathrm{O}_{3}$ & 291.2314, 273.2210, 255.2104, 207.1739, 199.1477, 191.1429, 175.1480 \\
\hline 20 & 16.65 & 335.2207 & 381.2254 & $359.2176[\mathrm{M}+\mathrm{Na}]^{+}$ & $\mathrm{C}_{20} \mathrm{H}_{32} \mathrm{O}_{4}$ & $319.2257,301.2152,283.2047,273.2204,255.2104,221.1533$ \\
\hline 21\# & 16.87 & 321.2061 & 367.2113 & --- & $\mathrm{C}_{19} \mathrm{H}_{30} \mathrm{O}_{4}$ & $305.2112,287.2007,259.2059,241.1946,231.2101,221.1540,175.1487$ \\
\hline 22 & 16.94 & 333.2064 & 379.2114 & $\begin{array}{c}335.2225[\mathrm{M}+\mathrm{H}]^{+} \\
357.2048[\mathrm{M}+\mathrm{Na}]^{+}\end{array}$ & $\mathrm{C}_{20} \mathrm{H}_{30} \mathrm{O}_{4}$ & $\begin{array}{c}317.2118,303.2327,299.2014,285.2218,271.2065,253.1960,221.1547 \\
207.1751,175.1487\end{array}$ \\
\hline 23 & 17.03 & 335.2215 & 381.2254 & $\begin{array}{l}337.2387[\mathrm{M}+\mathrm{H}]^{+} \\
673.4677[2 \mathrm{M}+\mathrm{H}]^{+}\end{array}$ & $\mathrm{C}_{20} \mathrm{H}_{32} \mathrm{O}_{4}$ & $\begin{array}{c}319.2274,301.2170,289.2174,273.2222,255.2122,221.1542,193.1231 \\
175.1484\end{array}$ \\
\hline $24 \#$ & 17.16 & 349.2016 & 395.2074 & --- & $\mathrm{C}_{20} \mathrm{H}_{30} \mathrm{O}_{5}$ & $\begin{array}{c}333.2086,315.1972,287.2021,269.1918,247.1706,243.2122,235.1702 \\
221.1907,203.1807\end{array}$ \\
\hline 25 & 17.46 & 335.2232 & 381.2286 & $\begin{array}{c}337.2384[\mathrm{M}+\mathrm{H}]^{+} \\
354.2652\left[\mathrm{M}+\mathrm{H}_{2} \mathrm{O}\right]^{+} \\
\end{array}$ & $\mathrm{C}_{20} \mathrm{H}_{32} \mathrm{O}_{4}$ & $\begin{array}{c}319.2277,301.2173,289.2173,273.2225,255.2121,221.1546,207.1761 \\
199.1497,193.1228,175.1493\end{array}$ \\
\hline 26 & 17.73 & 347.1849 & 393.1899 & $349.2000[\mathrm{M}+\mathrm{H}]^{+}$ & $\mathrm{C}_{20} \mathrm{H}_{28} \mathrm{O}_{5}$ & $303.1945,285.1851,274.2733,240.2318,221.1531,207.1741,175.1471$ \\
\hline 27 & 18.01 & 335.2225 & 381.2278 & $\begin{array}{l}359.2196[\mathrm{M}+\mathrm{Na}]^{+} \\
695.4498[2 \mathrm{M}+\mathrm{Na}]^{+}\end{array}$ & $\mathrm{C}_{20} \mathrm{H}_{32} \mathrm{O}_{4}$ & $319.2268,301.6121,273.2212,255.2112,221.1540,199.1494,175.1490$ \\
\hline
\end{tabular}


Table 1. Cont.

\begin{tabular}{|c|c|c|c|c|c|c|}
\hline \multirow{2}{*}{ Peak No. } & \multirow{2}{*}{$\begin{array}{l}\text { Retention Time } \\
(\min )\end{array}$} & \multicolumn{2}{|c|}{$\mathrm{ESI}^{-}, \mathrm{m} / \mathbf{z}^{*}$} & \multirow{2}{*}{$\mathrm{ESI}^{+}, \mathrm{m} / \mathbf{z}$} & \multirow{2}{*}{ Formula } & \multirow{2}{*}{ MS/MS Fragment Ions in Positive Mode ** } \\
\hline & & {$[\mathbf{M}-\mathbf{H}]^{-}$} & {$[\mathrm{M}+\mathrm{COOH}]^{-}$} & & & \\
\hline $28 \#$ & $\begin{array}{c}18.08 \\
\text { (acromatin C) }\end{array}$ & 335.2226 & 381.2281 & $690.4946\left[2 \mathrm{M}+\mathrm{H}_{2} \mathrm{O}\right]^{+}$ & $\mathrm{C}_{20} \mathrm{H}_{32} \mathrm{O}_{4}$ & $\begin{array}{c}319.2274,301.2170,273.2220,255.2115,235.1695,221.1543,199.1485 \\
193.1228,175.1493\end{array}$ \\
\hline 29 & 18.35 & 335.2228 & 381.228 & $359.2162[\mathrm{M}+\mathrm{Na}]^{+}$ & $\mathrm{C}_{20} \mathrm{H}_{32} \mathrm{O}_{4}$ & $\begin{aligned} 319.2274,301.2170,273.2220, & 255.2115,235.1698,221.1543,207.1731, \\
& 175.1493\end{aligned}$ \\
\hline 30 & 18.65 & --- & --- & $\begin{array}{c}345.2425[\mathrm{M}+\mathrm{Na}]^{+} \\
667.4901[2 \mathrm{M}+\mathrm{Na}]^{+}\end{array}$ & $\mathrm{C}_{20} \mathrm{H}_{34} \mathrm{O}_{3}$ & $\begin{array}{c}305.2476,287.2370,275.2368,269.2266,257.2272,207.1748,189.1643, \\
177.1639\end{array}$ \\
\hline 31 & 18.79 & --- & --- & $662.5363\left[2 \mathrm{M}+\mathrm{H}_{2} \mathrm{O}\right]^{+}$ & $\mathrm{C}_{20} \mathrm{H}_{34} \mathrm{O}_{3}$ & $\begin{array}{c}305.2482,287.2376,275.2368,269.2271,257.2288,229.1962,207.1753 \\
189.1646,177.1646,161.1337,149.1328\end{array}$ \\
\hline 32 & 18.84 & 335.2231 & 381.2287 & $\begin{array}{c}359.2205\left[\mathrm{M}+\mathrm{Na}^{+}\right. \\
690.4948\left[2 \mathrm{M}+\mathrm{H}_{2} \mathrm{O}\right]^{+} \\
695.4514[2 \mathrm{M}+\mathrm{Na}]^{+}\end{array}$ & $\mathrm{C}_{20} \mathrm{H}_{32} \mathrm{O}_{4}$ & $\begin{array}{c}319.2279,305.2486,301.2169,287.2375,273.2223,255.2117,221.1548 \\
207.1755,199.1490,189.1647,175.1492\end{array}$ \\
\hline 33 & 19.20 & 349.2385 & 395.2438 & $\begin{array}{c}368.2815\left[\mathrm{M}+\mathrm{H}_{2} \mathrm{O}\right]^{+} \\
718.5308\left[2 \mathrm{M}+\mathrm{H}_{2} \mathrm{O}\right]^{+}\end{array}$ & $\mathrm{C}_{21} \mathrm{H}_{34} \mathrm{O}_{4}$ & $\begin{array}{c}333.2448,319.2286,301.2179,283.2076,273.2235,255.2127,235.1706, \\
221.1554,207.1403,193.1242,175.1493,161.1339\end{array}$ \\
\hline 34 & 19.31 & 349.2379 & 395.2432 & --- & $\mathrm{C}_{21} \mathrm{H}_{34} \mathrm{O}_{4}$ & $\begin{array}{c}335.2238,319.2288,301.2180,289.2183,283.2069,273.2222,255.2126, \\
221.1554,207.1403,193.1242,175.1493,161.1339\end{array}$ \\
\hline 35 & 19.45 & 335.2223 & 381.2276 & $\begin{array}{l}359.2200[\mathrm{M}+\mathrm{Na}]^{+} \\
673.4678[2 \mathrm{M}+\mathrm{H}]^{+}\end{array}$ & $\mathrm{C}_{20} \mathrm{H}_{32} \mathrm{O}_{4}$ & $\begin{array}{c}319.2267,301.2168,291.2322,273.2218,255.2110,221.1540,207.1749, \\
203.1799,189.1640,175.1494\end{array}$ \\
\hline $36 \#$ & $\begin{array}{c}19.52 \\
\text { (acromatin B) }\end{array}$ & --- & --- & $\begin{array}{l}345.2401[\mathrm{M}+\mathrm{Na}]^{+} \\
667.4901[2 \mathrm{M}+\mathrm{Na}]^{+}\end{array}$ & $\mathrm{C}_{20} \mathrm{H}_{34} \mathrm{O}_{3}$ & $\begin{array}{c}305.2476,287.2370,275.2368,269.2266,257.2271,207.1748,189.1643, \\
177.1639,161.1328,149.1325\end{array}$ \\
\hline $37 \#$ & $\begin{array}{c}20.17 \\
\text { (acromatin A) }\end{array}$ & --- & --- & $\begin{array}{l}658.5023\left[2 \mathrm{M}+\mathrm{H}_{2} \mathrm{O}\right]^{+} \\
663.4627[2 \mathrm{M}+\mathrm{Na}]^{+}\end{array}$ & $\mathrm{C}_{20} \mathrm{H}_{32} \mathrm{O}_{3}$ & $\begin{array}{c}\text { 303.2314, 285.2208, 275.2384, 257.2264, 205.1589, 201.1648, 187.1484, } \\
177.1638,149.1330\end{array}$ \\
\hline 38 & 22.20 & 319.2278 & 365.2329 & --- & $\mathrm{C}_{20} \mathrm{H}_{32} \mathrm{O}_{3}$ & $\begin{array}{c}303.2325,285.2217,257.2268,233.1548,221.1542,201.1646,175.1483 \\
163.1487,147.1175\end{array}$ \\
\hline
\end{tabular}

\# Represented compounds that were identified with reference substances. ${ }^{*}$ All compounds were detected using the dominant formate adduct ions [M $+\mathrm{HCOO}^{-}$and deprotonated molecule ions $\left[\mathrm{M}-\mathrm{H}^{-} .{ }^{* *}\right.$ the data obtained under positive mode offered more information on fragment ions and the positive mode was then chosen for structural elucidation. --- Represented no corresponded ions were observed. 


\subsection{Optimization of Sample Preparation and UHPLC-QTOF-MS Analysis Conditions}

The extract parameters were optimized in order to obtain a higher extraction efficiency, including the following: the type of extraction method (ultrasonic and refluxing); extraction solvent (different methanol/water ratio solvent of 70:30, 80:20, and 85:15, v/v); and extraction time (20,30, 45, and $60 \mathrm{~min})$. The chromatograms of $B$. aromatica extract with different extraction conditions were available in Supplementary Materials (online at www.mdpi.com/1420-3049/24/17/3073/s1). The results were evaluated by the number of detected peaks after UPLC-QTOF-MS analysis. In the end, ultrasonic extraction conducted for $45 \mathrm{~min}$ with $80 \%$ methanol $(v / v)$ as a solvent was selected as the optimal extraction conditions for crude sample preparation.

The UHPLC-Q-TOF-MS conditions, such as the column type, the composition of mobile phase, ionization mode, capillary voltage, and collision energy, were also evaluated to get a shorter analytical time and satisfactory separation effect. The mobile phase additives may have a significant influence on signal response. It was found that the aqueous mobile phase containing formic acid $(0.1 \% v / v)$ could improve the peak shape and give higher ionization efficiency, especially that of trace peaks. Thus, a gradient elution system composed of acetonitrile- $0.1 \%$ aqueous formic acid was chosen as the eluting solvent system to give the optimal chromatographic peak shapes and resolution. In order to shorten analytical time and obtain satisfactory separation, two RP-C ${ }_{18}$ columns, Waters ACQUITY UPLC BEH C18 $(100 \times 2.1 \mathrm{~mm}, 1.7 \mu \mathrm{m})$ and ACQUITY UPLC HSS T3 $(100 \times 2.1 \mathrm{~mm}, 1.8 \mu \mathrm{m})$, flow rate $(0.3 \mathrm{~mL} / \mathrm{min}$, $0.4 \mathrm{~mL} / \mathrm{min}, 0.5 \mathrm{~mL} / \mathrm{min}$, and $0.6 \mathrm{~mL} / \mathrm{min}$ ) and column temperature at $30^{\circ} \mathrm{C}, 35^{\circ} \mathrm{C}$, and $40{ }^{\circ} \mathrm{C}$ were evaluated. Finally, ACQUITY UPLC HSS T3 column $(100 \times 2.1 \mathrm{~mm}, 1.8 \mu \mathrm{m})$ with the temperature at $35^{\circ} \mathrm{C}$ and flow rate of $0.5 \mathrm{~mL} / \mathrm{min}$ were chosen to obtain optimal chromatographic results. MS spectra were scanned at both positive and negative modes. The positive scanning mode was selected due to its higher ionization efficiency, and higher abundance fragment ions, even at low collision energy. Meanwhile, the precursor ions prone to form the $\left[\mathrm{M}+\mathrm{HCOO}^{-}\right.$quasimolecular ions were scanned under a negative scanning mode, which helped to confirm the molecular formula. The collision energy was optimized in the range of 20-60 V to obtain better MS/MS spectra results for the FSKD. In general, low collision energy is applied to ions with a low molecular weight to produce satisfactory fragment ions. In contrast, large molecules require high collision energy to obtain more fragment ions.

\subsection{Establishment of the MDF Filtration Method}

The MDF strategy has been applied to greatly improve the efficiency of the identification of bioactive constituents in TCM [23-25]. The components share the same core structure but have different substituent groups, which result in relatively narrow and defined mass defect shifts. Hence, in order to follow the MDF strategy, it was essential to define the mass defect value based on the combination of core structure and substituents.

On the basis of the concept of MDF described above, the first step was to ensure filtering reference skeleton based on published forskolin analogues [19,21,22]. The next step was to establish the mass defect range based on the core structure and substituent group combination. Then, filtration was applied to the chromatogram based on the setting expressed as central formula \pm mass defect tolerance. Finally, background ions were automatically removed, and characteristic ions remained visible after screening. In this study, the filtering parameters were established using the "accurate mass filter" function in MassLynx 4.1 software (Waters Corp., Milford, MA, USA). On the basis of the information published on these compounds, the filter reference was determined as 8, 13-epoxy-14 ene labdane diterpenes $\left(\mathrm{C}_{20} \mathrm{H}_{34} \mathrm{O}\right)$ and is illustrated in Figure 2. 


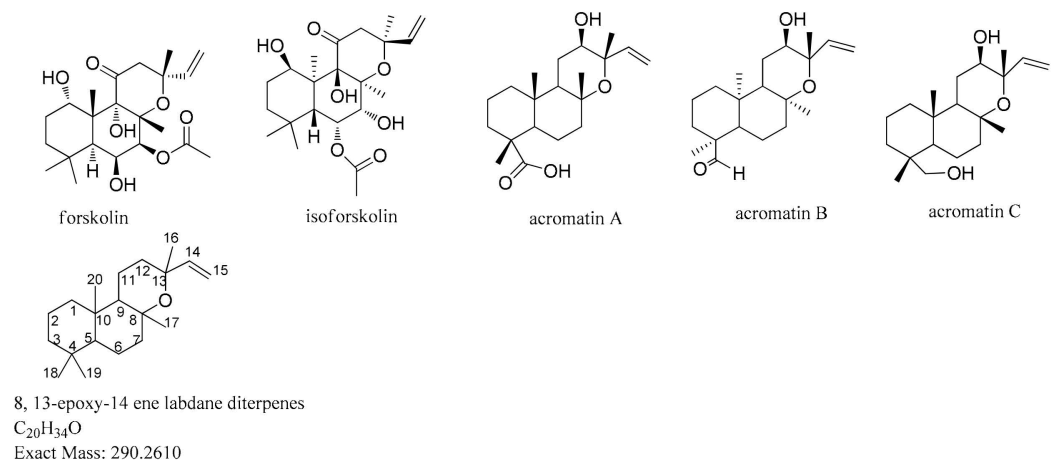

Figure 2. The chemical structure of reference compounds.

The substituents of the core structure mainly included carbonyl-function at the C-11 position, hydroxylation at C-1, C-6, C-7, and C-12 positions, acetylation or deacetylation, and other oxidized derivatives. The mass defect values were different between various substituents, with both carbonylation and acetylation increasing the mass defect value while hydroxylation decreased the mass defect value. On the basis of extract mass summaries of published forskolin analogues and mass defect value of the various substituents, the exact mass value was set on the $\mathrm{X}$-axis and the mass defect value on the Y-axis. The mass defect distribution diagram obtained is shown in Figure 3. It is interesting to note that all the components were found to be clustered in an elliptical range. Thus, the calculated minimum and maximum mass defect values of the labdane-type diterpenoids were found to be in the range of $0.2171-0.2788 \mathrm{Da}$, while the mass ranged from $280-460 \mathrm{Da}$. Therefore, the filtering template used for FSKD screening was set as follows: mass range 280-460 Da, MDF value set at $0.25 \mathrm{Da}$, with an upregulation of $30 \mathrm{mDa}$ and downregulation of $40 \mathrm{mDa}$. The mass error of the predicted chemical formula should be less than 10.00 ppm, while the element composition was set at C (18-25), H (28-40), and $\mathrm{O}(2-7)$.

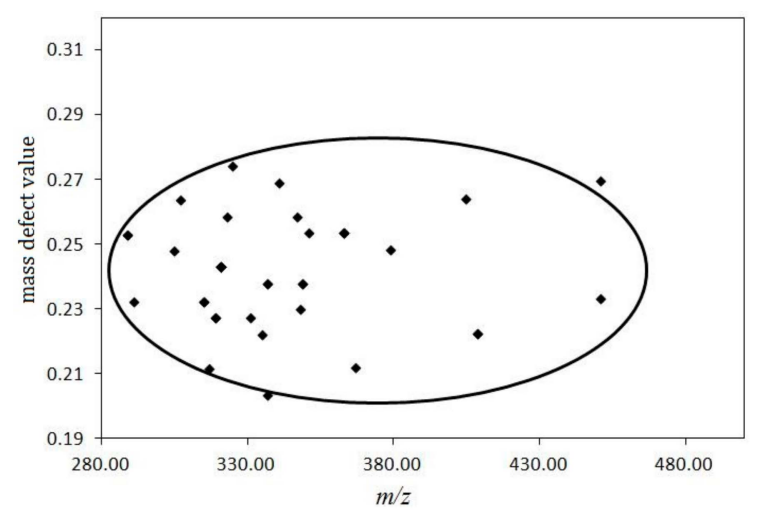

Figure 3. Mass defect filtering value distribution of 8, 13-epoxy-14 ene labdane type diterpenes.

\subsection{FSKD Analogue Identification After Filtration Using the MDF Approach}

After filtration using the optimized MDF approach, all interfering ions with mass defects that were significantly not within the filter window were excluded. The base peak intensity (BPI) chromatograms before and after filtration are shown in Figure 4. The noise level of the filtered chromatogram was much lower than that of the chromatogram without MDF filtration. As a result, a total of 38 peaks of the potential FSKD were filtered out within 28 min of chromatographic running time (Table 1). Similar types of chemical structures always possess similar MS/MS fragmentation behaviors and lead to common characteristic ions $[8,9,23]$. The fragment ions of each filtered peak are listed on Table 1 . The accurate mass and element composition of the precursor ions and fragment ions were calculated using the tool of "elemental composition" of MassLynx V 4.1 software. The mass error of the predicted chemical formula of less than $10.00 \mathrm{ppm}$ were selected as candidate compounds. Meanwhile, 
MassFragmentTM software was used to assist with the elucidation of chemical structure based on a scoring system. The structural identification of the FSKDs were further confirmed using reference compounds, published literature, the MS/MS fragmentation pathway, key product ions filtration, SciFinder, ChemSpider, and other online databases. All related data of the identified components are summarized in Table 1.

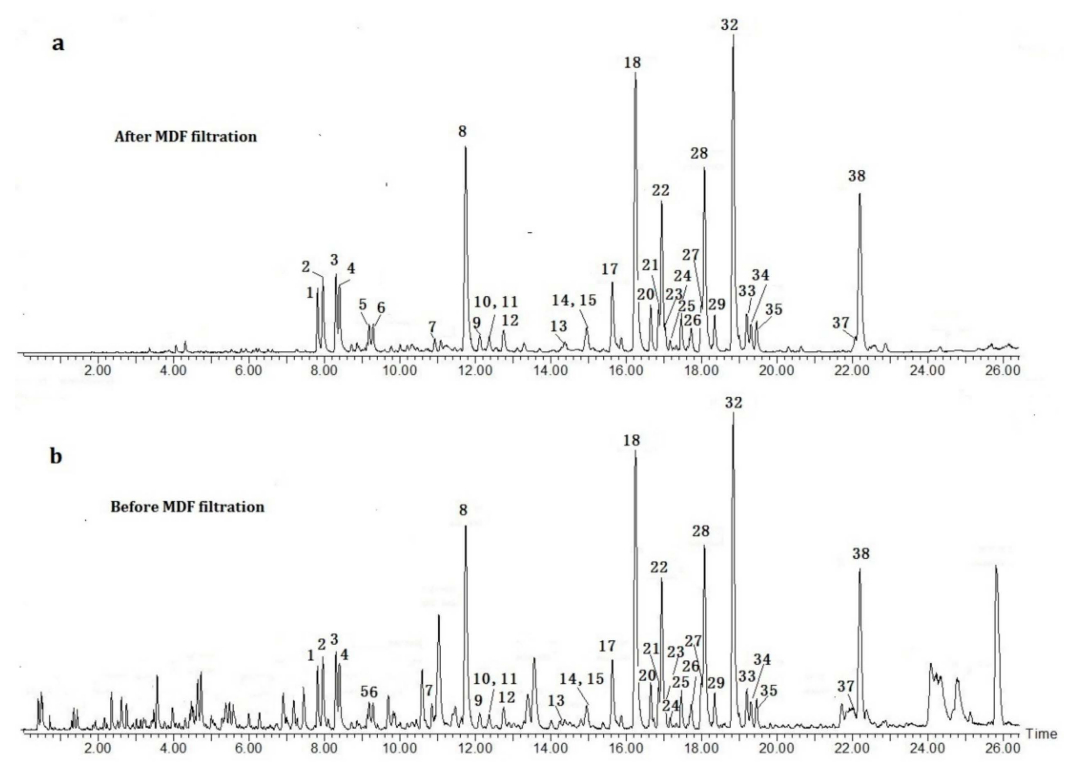

Figure 4. The ultra-high-performance liquid chromatography tandem quadrupole time-of-flight mass spectrometry (UHPLC-QTOF-MS) base peak intensity (BPI) chromatograms of B. aromatica.: (a) After MDF filtration and (b) Before MDF filtration.

The cleavage pathways of FSKDs of B. aromatica are proposed based on MS/MS data of the reference compounds. In previous research, diterpene compounds with a similar skeleton were found in B. aromatica, of which the structure belongs to 8,13-epoxy-14 ene labdane type diterpenes, and it is similar to the structure of forskolin. Until now, five FSKDs have been isolated from B. aromatica by our group. Three of them, acromatin A, acromatin B and acromatin $\mathrm{C}$, together with another two commercial standard compounds, forskolin and isoforskolin, were employed as template structures to study the fragmentation patterns of the FSKDs, which can subsequently enhance the comprehensive identification of other FSKDs in B. aromatica with the same core skeleton.

\subsubsection{Structural Elucidation of Acromatin A, Acromatin B, and Acromatin C}

On the basis of previous studies, compounds acromatin A, acromatin B, and acromatin C extracted from $B$. aromatica were isolated and characterized by our team and were identified using UV, IR, HRMS, and NMR. Their chemical structures are shown in Figure 2. The structures of acromatin A, acromatin B, and acromatin $C$ were found to share the same core skeleton of 8,13-epoxy-14 ene labdane diterpenes, with only differences in chemical configurations of the substituent group at the C-4 position, for which the substitutions groups were carboxyl, aldehyde, and methylene hydroxyl for acromatin $\mathrm{A}$, acromatin $\mathrm{B}$, and acromatin $\mathrm{C}$, respectively. Unlike forskolin, no carbonyl group was substituted at the C-11 position and no acetyl group substitution at the C-6 and C-7 positions was found in these FSKDs extracted from $B$. aromatica. Their main fragmentation pathway was the cleavage of $\mathrm{COOH}, \mathrm{CHO}$, and $\mathrm{CH}_{2} \mathrm{OH}$ at $\mathrm{C}-4$ and the neutral losses of $\mathrm{H}_{2} \mathrm{O}$ groups, along with the cleavage of the $\mathrm{C}_{9}-\mathrm{C}_{11}$ and $\mathrm{C}_{8}-\mathrm{O}-\mathrm{C}_{13}$ bonds of the $\mathrm{C}$-ring.

As regards to acromatin $C$, the deprotonated molecular ion $\left(m / z 335.2226,[\mathrm{M}-\mathrm{H}]^{-}\right)$was observed at $t_{R}=18.08$ min under negative ionization mode and adductive ion $m / z 690.4946\left[2 \mathrm{M}+\mathrm{H}_{2} \mathrm{O}\right]^{+}$under the positive mode. The elemental composition of the quasimolecular ions were calculated to be $\mathrm{C}_{20} \mathrm{H}_{32} \mathrm{O}_{4}$ using the "elemental composition" of MassLynx v4.1 software. It is notable that the SFKDs 
in B. aromatica are prone to form stable precursor ions $[\mathrm{M}-\mathrm{H}]^{-}$or $[\mathrm{M}+\mathrm{COOH}]^{-}$under the negative scanning mode, however, it is difficult to break these down to obtain fragment ions even under high collision energy. In contrast, the fragmentation ions easily formed under the positive ionization mode, even at low collision energy ( $6 \mathrm{~V})$. Therefore, in our study, both negative and positive scanning modes were used to obtain more information for structural elucidation of SFKDs in B. aromatica.

As shown in Figure 5, under positive ionization mode, the main product ions at $m / z 319.2274$ $\left[\mathrm{M}-\mathrm{H}_{2} \mathrm{O}\right]^{-}$and $301.2170\left[\mathrm{M}-2 \mathrm{H}_{2} \mathrm{O}\right]^{-}$corresponded to the successive neutral loss of $\mathrm{H}_{2} \mathrm{O}$. There was a $46 \mathrm{Da}$ difference between the fragment ion at $\mathrm{m} / \mathrm{z} 319.2274$ and 273.2220 , indicating the presence of a carboxyl group. The product ion at $\mathrm{m} / \mathrm{z} 255.2115$ was produced by cleavage of the ion at $\mathrm{m} / \mathrm{z}$ 273.2220 at the $\mathrm{C}_{8}-\mathrm{O}-\mathrm{C}_{13}$ bond and the loss of one $\mathrm{H}_{2} \mathrm{O}$ group, while the product ion at $\mathrm{m} / z 175.1485$ was produced by cleavage of the $C_{9}-C_{11}$ bond. Additionally, fragment ions at $m / z 255.2115,235.1695$, and 221.1543 corresponded to the successive loss of the formic acid group, the cleavage of $C_{9}-C_{11}$, and $\mathrm{C}_{11}-\mathrm{C}_{12}$, respectively. As for the low mass fragments, such as that at $m / z 145.1005\left(\mathrm{C}_{11} \mathrm{H}_{13}\right)$ and $\mathrm{m} / \mathrm{z}$ $133.1010\left(\mathrm{C}_{10} \mathrm{H}_{13}\right)$, they were derived from the A-ring and B-ring segments. In brief, the proposed fragmentation pathways of the SFKDs were mainly derived from the neutral losses of $\mathrm{COOH}, \mathrm{CHO}$, and $\mathrm{CH}_{2} \mathrm{OH}$ at $\mathrm{C}-4$ and $\mathrm{H}_{2} \mathrm{O}$, the cleavage of $\mathrm{C}_{8}-\mathrm{O}-\mathrm{C}_{13}$, and then the cleavage of $\mathrm{A}$ and $\mathrm{B}$ rings. Notably, ions at $\mathrm{m} / \mathrm{z} 273,255,221$, and 175 were found to be the characteristic fragment ions of these types of SFKDs. The prominent fragmentation pathway proposed for acromatin C is shown in Figure 4, which is expected to facilitate the characterization of SFKDs after filtration using the MDF method.
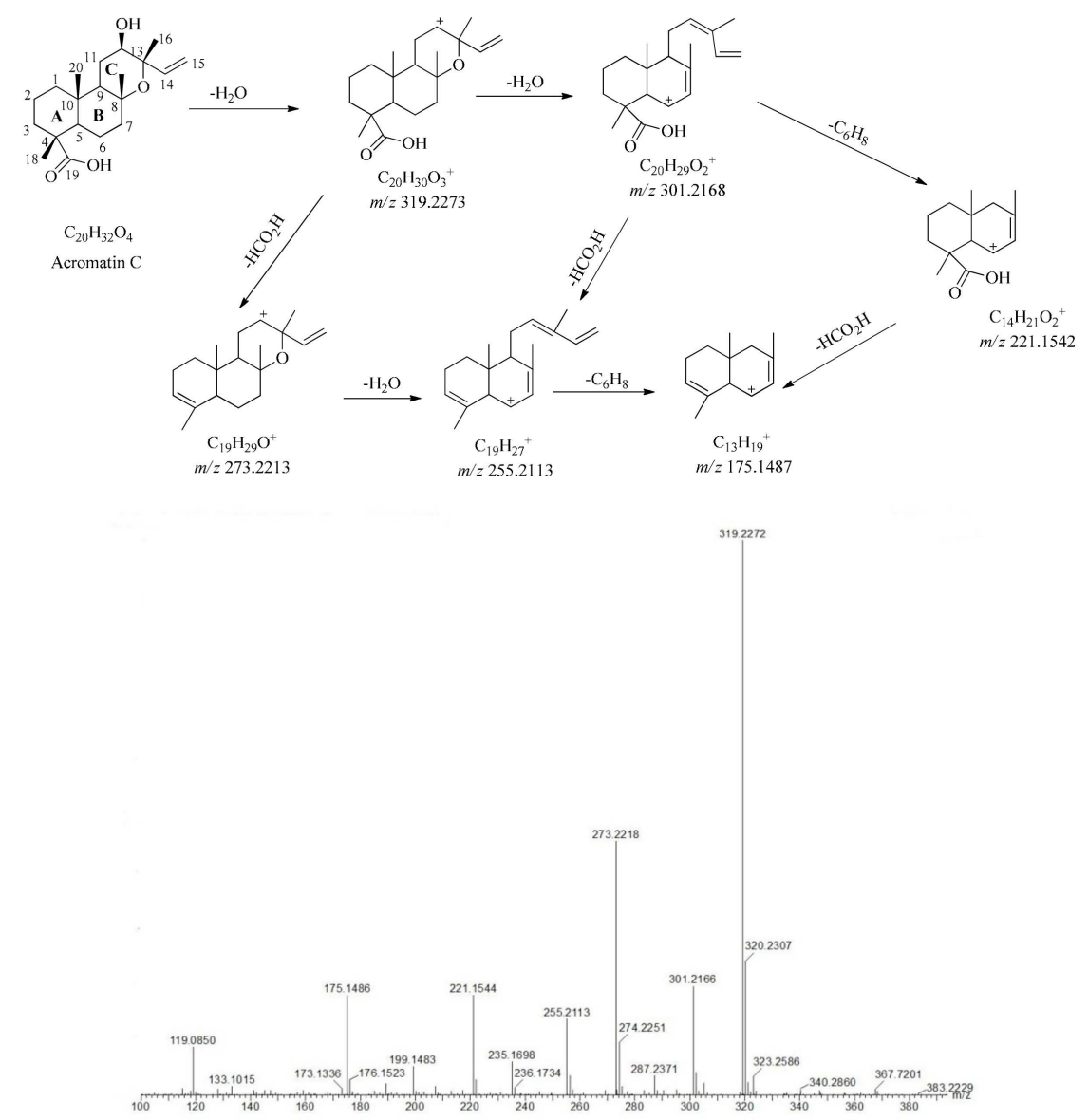

Figure 5. Proposed cleavage pathway and the MS/MS spectra of acromatin C.

The compounds acromatin A and acromatin B share the same core frame structure with acromatin $\mathrm{C}$, with differences in the substituent group at the $\mathrm{C}-4$ position. Similar to acromatin $\mathrm{C}$, the cleavage pathways of acromatin $A$ and acromatin $B$ mainly include the neutral losses of $\mathrm{H}_{2} \mathrm{O}, \mathrm{CO}$, and 
$\mathrm{CH}_{2} \mathrm{O}$, and the cleavage of the $\mathrm{C}_{8}-\mathrm{O}-\mathrm{C}_{13}$ bond in the C-ring. Fragmentation is always triggered by rearrangement of the A-ring, resulting in the formation of a seven-member ring when the C-4 position is substituted by a $-\mathrm{CH}_{2} \mathrm{OH}$ group. As shown in Figure 6, acromatin $\mathrm{B}\left(\mathrm{t}_{\mathrm{R}}=20.17 \mathrm{~min}\right)$ produces the quasimolecular ion at $m / z 658.5023\left[2 \mathrm{M}+\mathrm{H}_{2} \mathrm{O}\right]^{+}$and $663.4627[2 \mathrm{M}+\mathrm{Na}]^{+}$under positive ionization mode, with a molecular formula of $\mathrm{C}_{20} \mathrm{H}_{34} \mathrm{O}_{3}$. Fragment ions $m / z 305.2476$ and 287.2370 are derived from the successive loss of $\mathrm{H}_{2} \mathrm{O}$, accompanied by the rearrangement of the A-ring to form a seven-member ring, followed by the cleavage of the $\mathrm{C}_{8}-\mathrm{O}-\mathrm{C}_{13}$ bond forming the product ions at $m / z$ 269.2266 and 189.1643. Another cleavage pathway, with the neutral losses of $-\mathrm{CH}_{2} \mathrm{OH}$ directly without rearrangement of the A-ring, yields the product ions of $m / z 275.2375$ and further fragmentation of $m / z$ 275.2368 produces ions $m / z 257.2271$ and 177.1639 due to the cleavage of $\mathrm{C}_{8}-\mathrm{O}-\mathrm{C}_{13}$ bond of the C-ring (see Figure 6). The characteristic fragments for this type of SFKDs were also observed at $m / z 275,257$, and 177, which could be used for the identification of ions in this type of FSKD structure.

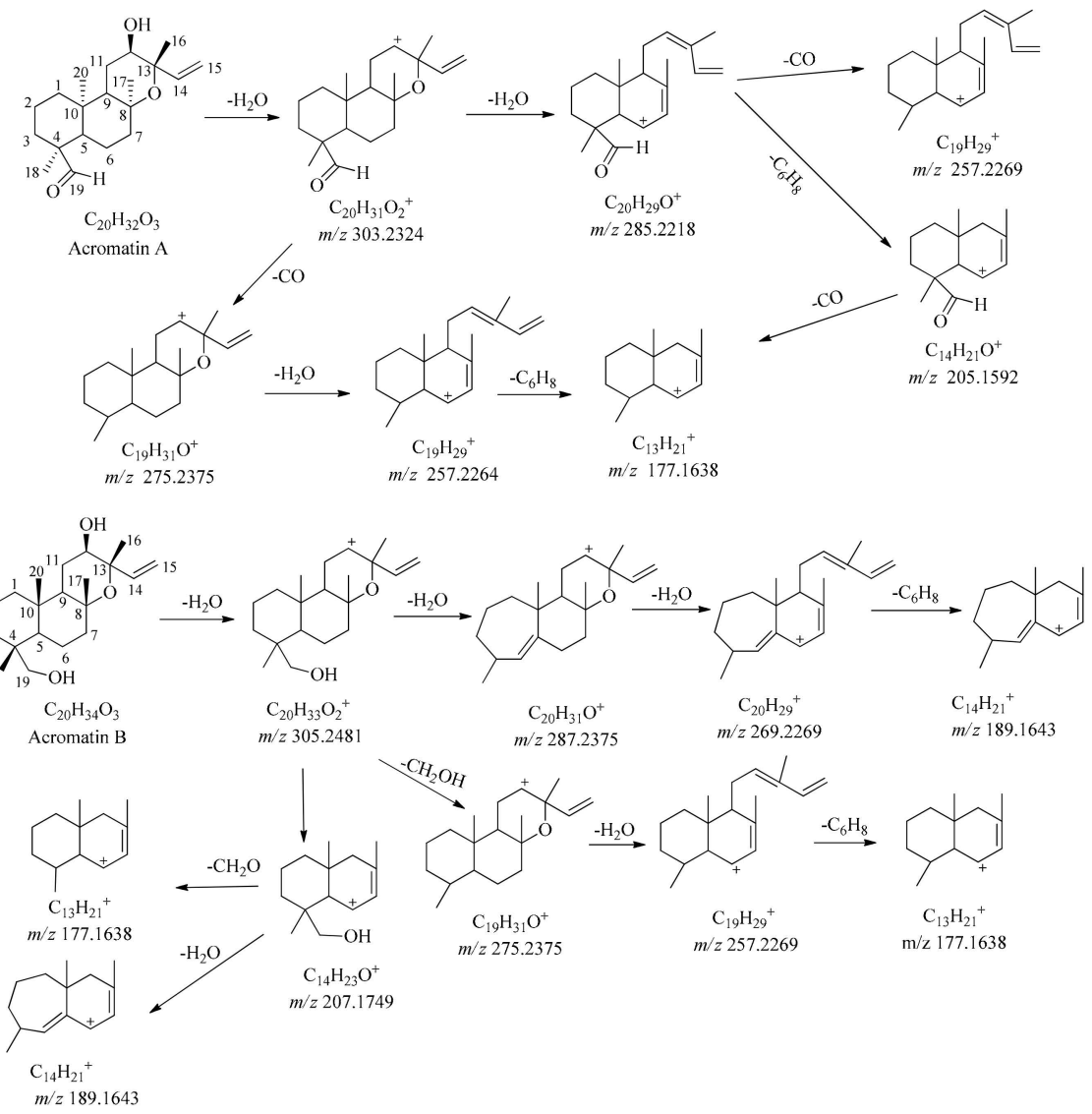

Figure 6. Proposed cleavage pathway and the MS/MS spectra of acromatin A and acromatin B.

\subsubsection{Structural Elucidation of Forskolin}

Forskolin shares a common core frame structure with acromatin A, acromatin B, and acromatin $\mathrm{C}$, which belong to the 8,13-epoxy-14ene labdane type of diterpenes. The differences are in the substituent group of the structure. There is usually a carbonyl substitution at the C-11 position of forskolin, dimethyl substitution at C-4, and acetyl substitution at the C-6 or C-7 position. Additionally, no hydroxyl group is substituted in the C-12 position (Figure 2). As for forskolin, the quasimolecular ion at $m / z 411.2383[\mathrm{M}+\mathrm{H}]^{+}$, with a molecular formula of $\mathrm{C}_{22} \mathrm{H}_{34} \mathrm{O}_{7}$, produced the predominant fragment ion at $m / z 393.2272\left[\mathrm{M}+\mathrm{H}-\mathrm{H}_{2} \mathrm{O}\right]^{+}, 375.2171\left[\mathrm{M}+\mathrm{H}-2 \mathrm{H}_{2} \mathrm{O}\right]^{+}, 357.2066\left[\mathrm{M}+\mathrm{H}-3 \mathrm{H}_{2} \mathrm{O}\right]^{+}$, and $315.1960\left[\mathrm{M}+\mathrm{H}-3 \mathrm{H}_{2} \mathrm{O}-\mathrm{CH}_{2} \mathrm{CO}^{+}\right.$, were subjected to the successive cleavages of hydroxyl $(-18)$, acetyl (-42) groups, respectively (Figure 7). Rearrangement was also observed in the cleavage pathway of forskolin. 


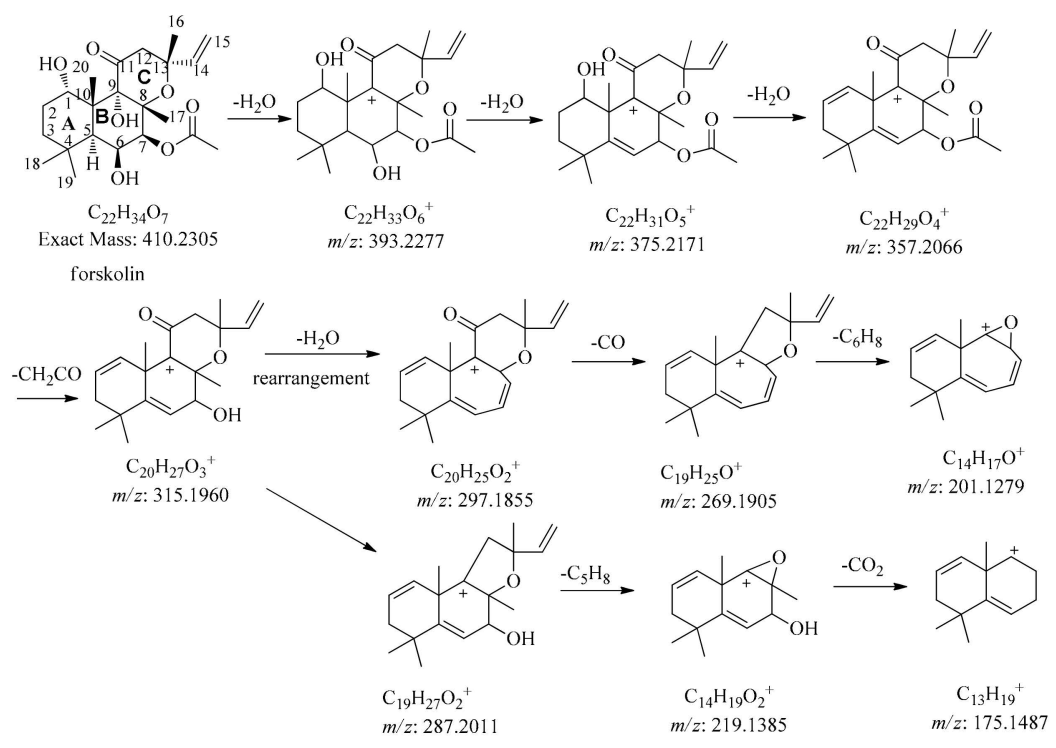

Figure 7. Proposed fragmentation pathway of forskolin.

Elimination of $-\mathrm{OH}$ leads to the formation of carbocation at the $\mathrm{C}-9$ position, which is prone to rearrangement of the methyl group at $\mathrm{C}-17$ to form a seven-member ring. The product ions at $\mathrm{m} / \mathrm{z}$ $297.1845\left[\mathrm{M}+\mathrm{H}-4 \mathrm{H}_{2} \mathrm{O}-\mathrm{CH}_{2} \mathrm{CO}\right]^{+}, 269.1905\left[\mathrm{M}+\mathrm{H}-4 \mathrm{H}_{2} \mathrm{O}-\mathrm{CH}_{2} \mathrm{CO}-\mathrm{CO}\right]^{+}$, and 201.1276 $\left[\mathrm{M}+\mathrm{H}-4 \mathrm{H}_{2} \mathrm{O}-\mathrm{CH}_{2} \mathrm{CO} \mathrm{CO}-\mathrm{C}_{5} \mathrm{H}_{8}\right]^{+}$are attributed to the neutral loss of $\mathrm{H}_{2} \mathrm{O}, \mathrm{CH}_{2} \mathrm{CO}$, and $\mathrm{CO}$, respectively, after rearrangement. The abundant fragments at $\mathrm{m} / \mathrm{z} 297$ and 201 are the characteristic ions attributed to this type of labdane diterpenes. At the same time, the neutral loss of an acetyl group $(-42)$ is also characteristic of the cleavage ascribed to this type of FSKDs.

\subsection{Accuracy Evaluation of the MDF Filtration Method}

The effectiveness of the MDF approach using the core substructure and substitution groups as a filter reference has been well demonstrated in the B. aromatica extract. After removal of the interfering compounds in B. aromatica extract using the above UHPLC-QTOF-MS and MDF filtration approach, the background noise of the BPI chromatograph (Figure 4) was significantly reduced and detection sensitivity was successfully enhanced. The efficiency of the MDF approach was also evaluated based on the number of FSKD compounds identified using UHPLC-QTOF-MS/MS platform divided by the number of compounds selected by MDF as potential FKSDs. Theoretically, all ions with a mass defect value within the setting range should be selected for further structural elucidation. However, some of these ions were not identified due to a weak response intensity, leading to the lack of MS/MS data and unavailability of fragment ions of the selected precursor ions under the MS conditions selected. In order to increase screening efficiency, these ions need to have a MS response intensity above $2.0 \mathrm{e}^{4}$ (positive mode) or $6.0 \mathrm{e}^{4}$ (negative mode) to be suitable for use in further research.

After filtering the FSKDs in B. aromatica extract using MDF, a total of 45 peaks were selected within the defined range. Then, UHPLC-QTOF-MS/MS was applied to characterize both target and non-target components in B. aromatica extract. Finally, a total of 38 potential FSKD precursor ions were selected based on accurate mass, fragment behaviors, and diagnostic ions, described above. All identified FSKDs were confirmed to be distributed in the established mass defect range. The MS/MS fragmentation patterns of the 38 FSKDs are summarized in Table 1. The BPI chromatogram of the FSKDs under the positive ion mode is shown in Figure 4. On the basis of the results of structural characterization, the accuracy of the MDF filtration method for FSKDs in B. aromatica was found to be $84.44 \%$.

It is notable that, many FSKD isomers were detected in the $B$. aromatica extract. These include peaks at $14,17,20,23,25$, and 29, the adduct ions $\left[\mathrm{M}+\mathrm{HCOO}^{-}\right.$at $\mathrm{m} / \mathrm{z} 381.2268$ and the deprotonated 
molecule ions $[\mathrm{M}-\mathrm{H}]^{-}$at $m / z$ 335.2226, which give the same molecular formula of $\mathrm{C}_{20} \mathrm{H}_{32} \mathrm{O}_{4}$, as with that of acromatin C. Meanwhile, the characteristic fragment ions at $m / z 319,301,273,255,221$, and 175 are consistent with that of acromatin $C$. Therefore, compound 14, 17, 20, 23, 25 and 29 are suggested to be isomers of acromatin C, which are FSKD analogues. The existence of diagnostic ions at $m / z 273.2225$, $255.2115,221.1545$, and 175.1496 indicate carbonyl group substitution at the C-4 position, similar to that of acromatin $C$.

Peaks 9, 10, 12 and 13 give rise to deprotonated molecule ions $[\mathrm{M}-\mathrm{H}]^{-}$at $m / z$ 353.23, with the same molecular formula as $\mathrm{C}_{20} \mathrm{H}_{34} \mathrm{O}_{5}$, indicating the isomer structure of each other. Characteristically, compounds 9, 10, 12, and 13 yield the product ions at $m / z 337,319,301,289,273,255,221$, and 175, which indicates that these compounds share the same or similar substructure. At the same time, the diagnostic fragment ions of 273, 255, 221, and 175 are consistent with that of acromatin $C$. Therefore, compound 9,10,12, and 13 were deduced to be FSKD analogues. Using the same strategy, other diterpenoids in B. aromatica extract were characterized as FSKDs.

It is noteworthy that the diagnostic fragment ions at $m / z 297$ and 201 were not detected in the filtered peaks and neither was the characteristic neutral loss of acetyl (-42) observed. Therefore, it was assumed, that they are different from the structure of forskolin, with no carbonyl group substituted at the C-11 position and no acetyl group substitution at C-6 and C-7 positions in these types of FSKDs detected in B. aromatica extract.

\section{Materials and Methods}

\subsection{Chemicals and Materials}

The authentic standard of forskolin and isoforskolin were purchased from the National Institutes for Food and Drug Control (Beijing, China). Acromatin A, acromatin B and acromatin C were isolated from B. aromatica in our laboratory and their structures were identified using ESI-MS and NMR. The purity was more than 98\% (determined by HPLC). Acetonitrile (HPLC-grade) and formic acid with a purity of $>98 \%$ were purchased from Merck KGaA (Darmstadt, Germany), and ultrapure water purified with a Milli-Q Academic system (Millipore, Bedford, MA, USA) was used for the LC/MS analysis. The structures of the reference compounds are summarized in Figure 2.

The herbal material was collected from Fengshan county, Hechi, Guangxi Province of China and authenticated by S. X. Feng as Blumea aromatica DC. and the voucher specimens (No. 153603) were deposited at the Herbarium Centre, Guangxi Botanical Garden of Medicinal Plants, Nanning, China.

\subsection{Preparation of Sample and Standard Solutions}

The air-dried sample of B. aromatica was pulverized into a powder and sieved through an 80-mesh screen. An aliquot of $0.5 \mathrm{~g}$ of dried B. aromatica powder was suspended in $20 \mathrm{~mL}$ of $80 \%$ methanol $(v / v)$ in a $25 \mathrm{~mL}$ volumetric flask and sonicated at $100 \mathrm{~Hz}$ for $45 \mathrm{~min}$. After reaching room temperature, the suspension was made up to $25 \mathrm{~mL}$ by adding $80 \%$ methanol $(v / v)$. The solutions obtained were centrifuged at 13,000 rpm for $10 \mathrm{~min}$, then filtered through $0.22 \mu \mathrm{m}$ filter units, before being injected into UHPLC-Q-TOF/MS systems.

Stock solutions: A specified amount of forskolin, isoforskolin, acromatin A, acromatin B, and acromatin $\mathrm{C}$ were dissolved in $80 \%$ methanol-water $(v / v)$ to obtain initial stock solutions at a concentration of $1.0 \mathrm{mg} / \mathrm{mL}$, and then stored at under $4{ }^{\circ} \mathrm{C}$ in a refrigerator. All solutions were filtered using a $0.22 \mu \mathrm{m}$ PTFE syringe filter before being injected for LC/MS analysis.

\subsection{UHPLC-QTOF/MS Conditions}

A Waters ACQUITY UHPLC I-Class system (Waters Corporation, Milford, MA, USA) was used to carry out the chromatographic separations. The analysis gradient elution with $0.1 \%(v / v)$ aqueous formic acid (A) and acetonitrile (B) was used as the mobile phase at a flow rate of $0.5 \mathrm{~mL} / \mathrm{min}$. The optimized gradient elution program was: 0-2.5 min, 5-10\% B; 2.5-4.5 min, 10-22\% B; 4.5-7.0 min, 22-28\% B; 
7.0-14.0 min, 28-55\% B; 14.0-20.0min, 55-60\% B; 20.0-22.0 $\mathrm{min}, 60-70 \%$ B; $22.0-25.0 \mathrm{~min}, 70-95 \%$ B; and 25.1-28.0 min, 5\% B. Chromatographic separation was achieved with an ACQUITY HSS T3 column $\left(100 \mathrm{~mm} \times 2.1 \mathrm{~mm}, 1.8 \mu \mathrm{m}\right.$; Waters, USA) at $35^{\circ} \mathrm{C}$. The sample injection volume was set at $2 \mu \mathrm{L}$.

MS/MS analysis was performed on a high-resolution quadrupole time-of-flight (QTOF-MS) system (Xevo G2-S, Waters Corporation, Manchester, UK), with a performance of resolution $>30,000$, mass accuracy $<1 \mathrm{ppm}$, and coupled with an electrospray ionization (ESI) interface. All samples were determined at both positive and negative ionization mode with mass ranging from 100 to $1200 \mathrm{Da}$ over a $28 \mathrm{~min}$ analysis time. LockSpray ${ }^{\mathrm{TM}}$ was used to ensure MS data accuracy and reproducibility. The leucine-enkephalin (Sigma-Aldrich, Saint Quentin Fallavier, France) was used as the lock reference mass, generating $[\mathrm{M}-\mathrm{H}]^{-}$and $[\mathrm{M}+\mathrm{H}]^{+}$at $\mathrm{m} / \mathrm{z} 554.2615$ and $\mathrm{m} / \mathrm{z} 556.2771$ at the negative and positive electrospray ionization mode, respectively, with a concentration of $400 \mathrm{ng} / \mathrm{mL}$ and flow rate of $5 \mu \mathrm{L} / \mathrm{min}$ during MS analysis to ensure accuracy during MS analysis. The lockspray scan time was set as $0.1 \mathrm{~s}$ and the interval was set to $20 \mathrm{~s}$.

The other QTOF-MS operating parameters were optimized as follows: nitrogen was used as the source of gas, while ultrahigh purity argon was used as the collision gas for collision induced dissociation (CID). The desolvation gas flow rate was set at $800 \mathrm{~L} / \mathrm{h}$ with a temperature of $350{ }^{\circ} \mathrm{C}$, and the cone gas was set at $20 \mathrm{~L} / \mathrm{h}$ and the cone voltage was set at $40 \mathrm{~V}$, the source temperature was set at $120^{\circ} \mathrm{C}$ and the capillary voltage was set at $2.7 \mathrm{kV}$ and $3.0 \mathrm{kV}$ at the negative and positive scanning modes, respectively. For the MS/MS experiments, an $\mathrm{MS}^{\mathrm{E}}$ experiment with a dynamic collision energy range of 30-50 V was conducted to obtain both precursor ions and fragment ions using one injection of the sample. The $\mathrm{MS}^{\mathrm{E}}$ parameters were set as follows: function $1: \mathrm{m} / \mathrm{z} 100-1200,0.2 \mathrm{~s}$ scan time, $0.02 \mathrm{~s}$ inter-scan delay, $40 \mathrm{~V}$ sample cone, low collision energy set at $6 \mathrm{~V}$; function 2: $\mathrm{m} / \mathrm{z} 50-1200,0.2 \mathrm{~s}$ scan time, $0.02 \mathrm{~s}$ inter-scan delay, $40 \mathrm{~V}$ sample cone, 30-50 V ramp high collision energy.

\subsection{Data Process}

The MDF method was followed using the "accurate mass filter" function of Masslynx 4.1 software. The molecular formulas were obtained using the "elemental composition" of Masslynx 4.1 software. The mass error of the predicted chemical formula lower than $10.00 \mathrm{ppm}$ was selected as the candidate compound. Meanwhile, MassFragmentTM software, which can automate structural assignment based on a particular scoring system, was applied to assist the elucidation of chemical structure and to ensure the accuracy and efficiency of MDF. The MS/MS fragment analysis using MassFragment ${ }^{\mathrm{TM}}$ was performed at the positive scanning mode. The key parameters were set as follows: maximum mass error, double-bond equivalent DBE 0-10; electron count, odd; maximum H deficit, 6; and fragment number of bonds, 4 .

\section{Conclusions}

In the present study, a powerful strategy was used to rapidly obtain the characteristic forskolin analogues of B. aromatica using a method of UHPLC-QTOF/MS coupled with MDF data filtration approach. Compared with the conventional method, the MDF strategy enables a majority of the interfering ions to be automatically filtered, allowing the original data to be analyzed more effectively, accurately, and rapidly. It could be used for the rapid analysis of other homologous families used in TCM, especially when there is a lack of literature and inaccessibility of standards of authentication.

A total of 38 FSKD precursor ions were characterized, or tentatively identified, in B. aromatica extract, for the first time. The newly discovered FSKDs significantly expand our understanding of the chemical constituents of B. aromatica, which is a potential alternative plant resource that contains forskolin-type diterpenoid active compounds. Accurate structural identification of chemical compounds in TCM requires integration of NMR, IR, UV, and MS data. The current DMF filtration strategy based on MS data is able to provide structural information of interested compounds used in TCM. Further research will be conducted at our lab to target the phytochemical and pharmacological activity of the FSKDs of important herbal medicines. 
Supplementary Materials: The following are available online at http://www.mdpi.com/1420-3049/24/17/3073/s1, Figure S1: Chromatograms of B. aromatica extract with different extract method, Figure S2: Chromatograms of B. aromatica extract with different extract solvent, Figure S3: Chromatograms of B. aromatica extract with different extract time.

Author Contributions: UHPLC method development and validation, L.H. and Z.Z.; sample preparation, C.Y. and B.Y.; data curation, L.W.; conceived and designed the experiments, Z.S., S.W. and J.M.; project administration and analyzed the data: L.H. and Z.S.; paper writing_-review and editing, Z.Z. and L.P. All authors read and approved the final manuscript.

Funding: This work was supported by the National Natural Science Foundation of China (No. 2015NSFC81460534); the Natural Science Foundation of Guangxi (No. 2013GXNSFDA019022, No. 2015GXNSFBA139118, and No. 2018GXNSFAA281139); and the Guangxi Botanical Garden of Medicinal Plants Research and Innovation Team Building Project (GYCH2019006 and GYCH2019008).

Conflicts of Interest: The authors declare no conflict of interest.

\section{Abbreviations}

$\begin{array}{ll}\text { UHPLC } & \text { Ultra-high } \\ \text { QToF } & \text { Quadrupole Time of Flight } \\ \text { MDF } & \text { Mass defect filter } \\ \text { FSKD } & \text { forskolin-type diterpenoids } \\ \text { TCM } & \text { Traditional Chinese medicines }\end{array}$

\section{References}

1. Zhang, L.; Shen, H.; Xu, J.; Xu, J.D.; Li, Z.L.; Wu, J.; Zou, J.T.; Wu, J.; Liu, L.F.; Li, S.L. UPLC-QTOF-MS/MS-guided isolation and purification of sulfur-containing derivatives from sulfur-fumigated edible herbs, a case study on ginseng. Food Chem. 2018, 246, 202-210. [CrossRef] [PubMed]

2. Zhu, H.L.; Lin, H.Q.; Tan, J.; Wang, C.Z.; Wang, H.; Wu, F.L.; Dong, Q.H.; Liu, Y.H.; Li, P.Y.; Liu, J.P. UPLC-QTOF/MS-Based Nontargeted Metabolomic Analysis of Mountain- and Garden-Cultivated Ginseng of Different Ages in Northeast China. Molecules 2019, 24, 33. [CrossRef] [PubMed]

3. He, L.L.; Zhang, Z.F.; Liu, Y.; Chen, D.Q.; Yuan, M.H.; Dong, G.T.; Luo, P.; Yan, Z.G. Rapid discrimination of raw and sulfur-fumigated Smilax glabra based on chemical profiles by UHPLC-QTOF-MS/MS coupled with multivariate statistical analysis. Food Res. Int. 2018, 108, 226-236. [CrossRef] [PubMed]

4. Wang, Y.H.; Meng, Y.H.; Zhai, C.M.; Wang, M.; Avula, B.; Yuk, J.; Smith, K.M.; Isaac, G.; Khan, I.A. The Chemical Characterization of Eleutherococcus senticosus and Ci-wu-jia Tea Using UHPLC-UV-QTOF/MS. Int. J. Mol. Sci. 2019, 20, 475. [CrossRef]

5. Rivera, G.A.; Vivas, D.B.; Alfonso, F.P.; Ibañez, E.; Cifuentes, A. Recent applications of high resolution mass spectrometry for the characterization of plant natural products. Trends Anal. Chem. 2019, 112, 87-101. [CrossRef]

6. Pan, H.Q.; Yao, C.L.; Yang, W.Z.; Yao, S.; Huang, Y.; Zhang, Y.B.; Wu, W.Y.; Guo, D.A. An enhanced strategy integrating offline two-dimensional separation and step-wise precursor ion list-based raster-mass defect filter: Characterization of indole alkaloids in five botanical origins of Uncariae Ramulus Cum Unicis as an exemplary application. J. Chromatogr. A 2018, 1563, 124-134. [CrossRef]

7. Zhou, W.; Shan, J.; Meng, M. A two-step ultra-high-performance liquid chromatography-quadrupole/time of flight mass spectrometry with mass defect filtering method for rapid identification of analogues from known components of different chemical structure types in Fructus Gardeniae-Fructus Forsythiae herb pair extract and in rat's blood. J. Chromatogr. A 2018, 1563, 99-123. [CrossRef]

8. Yang, B.; Li, H.; Ruan, Q.F.; Xue, Y.Y.; Cao, D.; Zhou, X.H.; Jiang, S.Q.; Yi, T.; Jin, J.; Zhao, Z.X. A facile and selective approach to the qualitative and quantitative analysis of triterpenoids and phenylpropanoids by UPLC/Q-TOF-MS/MS for the quality control of Ilex rotunda. J. Pharm. Biomed. Anal. 2018, 157, 44-58. [CrossRef]

9. Zhao, W.J.; Shang, Z.P.; Li, Q.Q.; Huang, M.R.; He, W.B.; Wang, Z.B.; Zhang, J.Y. Rapid Screening and Identification of Daidzein Metabolites in Rats Based on UHPLC-LTQ-Orbitrap Mass Spectrometry Coupled with Data-Mining Technologies. Molecules 2018, 23, 151. [CrossRef] 
10. Ekanayaka, E.A.; Celiz, M.D.; Jones, A.D. Relative mass defect filtering of mass spectra: A path to discovery of plant specialized metabolites. Plant Physiol. 2015, 167, 1221-1232. [CrossRef]

11. Asada, Y.; Li, W.; Terada, T.; Kuang, X.; Li, Q.; Yoshikawa, T.; Hamaguchi, S.; Namekata, I.; Tanaka, H.; Koike, K. Labdane-type diterpenoids from hairy root cultures of Coleus forskohlii, possible intermediates in the biosynthesis of forskolin. Phytochemistry 2012, 79, 141-146. [CrossRef] [PubMed]

12. Alasbahi, R.H.; Melzig, M.F. Forskolin and derivatives as tools for studying the role of cAMP. Pharmazie 2012, 67, 5-13. [CrossRef] [PubMed]

13. Ríos-Silva, M.; Trujillo, X.; Trujillo-Hernández, B.; Sánchez-Pastor, E.; Urzúa, Z.; Mancilla, E.; Huerta, M. Effect of chronic administration of forskolin on glycemia and oxidative stress in rats with and without experimental diabetes. Int. J. Med. Sci. 2014, 11, 448-452. [CrossRef] [PubMed]

14. Sapio, L.; Gallo, M.; Illiano, M.; Chiosi, E.; Naviglio, D.; Spina, A.; Naviglio, S. The Natural cAMP Elevating Compound Forskolin in Cancer Therapy: Is It Time? J. Cell Physiol. 2017, 232, 922-927. [CrossRef] [PubMed]

15. Wang, H.L.; Lou, C.Y.; Ma, N. Forskolin exerts anticancer roles in non-Hodgkin's lymphomas via regulating Axin/ $\beta$-catenin signaling pathway. Cancer Manag. Res. 2019, 11, 1685-1696. [CrossRef] [PubMed]

16. Du, X.; Shi, R.; Wang, Y.; Wu, W.; Sun, S.; Dai, Z.; Chen, C.; Weng, Z.; Li, X.; Liu, Q.; et al. Isoforskolin and forskolin attenuate lipopolysaccharide-induced inflammation through TLR4/MyD88/NF- $\mathrm{kB}$ cascades in human mononuclear leukocytes. Phytother. Res. 2019, 33, 602-609. [CrossRef]

17. Chen, Y.; Wen, J.G.; Feng, J.J.; Wang, Y.H.; Li, T.F.; Nurmi, K.; Eklund, K.K.; Xing, D. Forskolin attenuates the NLRP3 inflammasome activation and IL-1 $\beta$ secretion in human macrophages. Pediatr. Res. 2019, 1. [CrossRef]

18. Bodiwala, H.S.; Sabde, S.; Mitra, D.; Bhutani, K.K.; Singh, I.P. Anti-HIV diterpenes from Coleus forskohlii. Nat. Prod. Commun. 2009, 4, 1173-1175. [CrossRef]

19. Kavitha, C.; Rajamani, K.; Vadivel, E. Coleus forskohlii: A comprehensive review on morphology, phytochemistry and pharmacological aspects. J. Med. Plants Res. 2010, 4, 278-285.

20. Lan, M.S.; Luo, C.; Tan, C.H.; Chen, L.; Wei, S.; Zhu, D.Y. Study on chemical constituents of the ethyl acetate extract from Blumea aromatica. J. Chin. Med. Mater. 2012, 35, 229-231.

21. Xu, L.; Lu, J.; Li, W.; Kong, L. Studies on the chemical constituents in root of Coleus forskohlii. China J. Chin. Mater. Med. 2005, 30, 1753-1755.

22. Shan, Y.; Xu, L.; Lu, Y.; Wang, X.; Zheng, Q.; Kong, L.; Niwa, M. Diterpenes from Coleus forskohlii (WILLD.) BRIQ. (Labiatae). Chem. Pharm. Bull. 2008, 56, 52-56. [CrossRef]

23. Tan, T.; Luo, Y.; Zhong, C.C.; Xu, X.; Feng, Y.L. Comprehensive profiling and characterization of coumarins from roots stems, leaves, branches, and seeds of Chimonanthus nitens Oliv. using ultra-performance liquid chromatography/quadrupole-time-of-flight mass spectrometry combined with modified mass defect filter. J. Pharm. Biomed. Anal. 2017, 141, 140-148. [CrossRef]

24. Fu, L.L.; Ding, H.; Han, L.F.; Jia, L.; Yang, W.Z.; Zhang, C.X.; Hu, Y.; Zuo, T.T.; Gao, X.M.; Guo, D.A. Simultaneously targeted and untargeted multicomponent characterization of Erzhi Pill by offline two-dimensional liquid chromatography/quadrupole-Orbitrap mass spectrometry. J. Chromatogr. A 2019, 1584, 87-96. [CrossRef]

25. Ren, D.B.; Ran, L.; Yang, C.; Xu, M.L.; Yi, L.Z. Integrated strategy for identifying minor components in complex samples combining mass defect, diagnostic ions and neutral loss information based on ultra-performance liquid chromatography-high resolution mass spectrometry platform: Folium Artemisiae Argyi as a case study. J. Chromatogr. A 2018, 1550, 34-35. [CrossRef]

Sample Availability: Samples of the compounds acromatin A, acromatin B, and acromatin C are available from the authors.

(C) 2019 by the authors. Licensee MDPI, Basel, Switzerland. This article is an open access article distributed under the terms and conditions of the Creative Commons Attribution (CC BY) license (http://creativecommons.org/licenses/by/4.0/). 